\title{
Bilateral enucleation induces homeostatic plasticity in the dorsolateral geniculate nucleus of mice.
}

Authors: Ashish Bhandari ${ }^{1,2}$, Jennie Smith ${ }^{1}$, Matthew J. Van Hook ${ }^{1,3, *}$

\section{$\underline{\text { Affiliations: }}$}

1. Truhlsen Eye Institute, Department of Ophthalmology \& Visual Sciences, University of Nebraska Medical Center, Omaha, NE 68198

2. Department of Pharmacology \& Experimental Neuroscience, University of Nebraska Medical Center, Omaha, NE 68198

3. Department of Cellular \& Integrative Physiology, University of Nebraska Medical Center, Omaha, NE 61898

\section{*Correspondence:}

Dr. Matthew J. Van Hook

matt.vanhook@unmc.edu 


\section{$\underline{\text { Abstract }}$}

Within the nervous system, homeostatic mechanisms stabilize network activity following disruption by injury, disease, or degeneration. Vision loss and optic nerve injury in age-related diseases such as glaucoma might trigger homeostatic responses in direct retinal projection targets in the brain in adulthood. We tested this possibility using patch-clamp electrophysiology, optogenetics, and single-cell dendritic analysis to probe the effects of optic nerve injury and vision loss on dLGN thalamocortical (TC) relay neurons and their synaptic inputs following bilateral enucleation. Using vGlut2 immunostaining, we found that retinal axon terminals in the dLGN degenerated over several days post-enucleation, which corresponded with the loss of retinogeniculate $(\mathrm{RG})$ synaptic function as assessed with optogenetic stimulation of ganglion cell axons in acute brain slices. Analysis of TC neuron dendritic structure from single-cell dye fills revealed a gradual loss of dendrites proximal to the soma, where TC neurons receive the bulk of RG inputs. Surprisingly, there was little change to the frequency of miniature post-synaptic currents (mEPSCs), even two weeks post-enucleation, although we did find an increase in the relative proportion of mEPSCs with slower kinetics, hinting at a possible enhancement of corticogeniculate input. Whole-cell current clamp recordings showed that enucleation enhanced TC neuron action potential firing and input resistance, consistent with homeostatic scaling of intrinsic neuronal excitability following perturbation of synaptic inputs. Our findings show that degeneration of the retinal axons/optic nerve and loss of RG synaptic inputs induces structural and functional changes in TC neurons consistent with compensatory homeostatic plasticity in the dLGN.

Keywords: dLGN, homeostatic plasticity, retinogeniculate synapse, excitability, bilateral enucleation, thalamocortical 


\section{$\underline{\text { Introduction }}$}

The activity of neuronal networks in the brain is one of the most stable components of the nervous system and this stability is required throughout life to maintain functional connectivity for effective information transfer (Turrigiano, 1999, 2008; Turrigiano and Nelson, 2004; D’Angelo, 2010). This results from the nervous system's ability to monitor changes in network activity and compensate via modulation of neuronal structure, intrinsic excitability, and/or synaptic function (Abbott and Nelson, 2000; Darlington et al., 2002; Schulz, 2006; Beck and Yaari, 2008; Howland and Wang, 2008; Gainey et al., 2009; Turrigiano, 2012; Lambo and Turrigiano, 2013; Bliss et al., 2014; Hauser et al., 2014; Fernandes and Carvalho, 2016; Chowdhury and Hell, 2018; Meriney and Fanselow, 2019). This is known as homeostatic plasticity and is an important feature of the nervous system during learning and development as well as in disease.

Plasticity in cortical and sub-cortical structures has been reported during maturation as well as in adulthood in response to learning and memory or injury. One of the key structures of the visual system is the dorsolateral geniculate nucleus (dLGN), which receives direct projections from retinal ganglion cells, integrates visual responses (Mazade and Alonso, 2017; Monavarfeshani et al., 2017), and relays that information to the primary visual cortex (Sherman and Guillery, 2002; Chen et al., 2016). Disruption in the flow of information resulting from injury or disease will interrupt normal communication and may trigger compensatory mechanisms to counter the disruption. The developmental plasticity of the dLGN is well-established and involves pruning and strengthening of synaptic inputs from retinal ganglion cells, refinement of dLGN relay neuron dendritic branching, and maturation of intrinsic excitability (Chen and Regehr, 2000; Hooks and Chen, 2006, 2008; Bickford et al., 2010; Hong and Chen, 2011; Krahe et al., 2012; El-Danaf et al., 2015; Thompson et al., 2016; Litvina and Chen, 2017; Guido, 2018). A handful of studies have also documented plasticity in the dLGN in adult mouse, including in monocular deprivation (Jaepel et al., 2017; Rose and Bonhoeffer, 2018), monocular enucleation (Gonzalez et al., 2005), a mouse model of inflammatory demyelination (Araújo et al., 2017), and ocular hypertension (Bhandari et al., 2019). These studies have shown that alterations in visual function or optic nerve health lead to changes in inputs to the dLGN from retina and the cortex as well as changes in the structure of dLGN relay neurons (Yücel et al., 2001; Hayakawa and Kawasaki, 2010; Krahe and Guido, 2011; Ly et al., 2011; Krahe et al., 2012; You et al., 2012; El-Danaf et al., 2015; Pang et al., 2015; Araújo et al., 2017; Bhandari et al., 2019).

Given that plasticity in the dLGN has been well established during development as well as adulthood, it is still unknown how the mature dLGN responds to severe optic nerve injury. While we have previously explored the influence of ocular hypertension (Bhandari et al., 2019), which induces a lowlevel and chronic optic nerve injury and alteration in RGC output, our goal here was to use a more 
dramatic insult to probe plasticity processes in the dLGN. To accomplish this, we bilaterally enucleated adult mice to test the hypothesis that traumatic optic nerve injury will induce homeostatic plasticity in the dLGN. 


\section{$\underline{\text { Experimental Procedures }}$}

Animals

All procedures were approved by the Institutional Animal Care and Use Committee at the University of Nebraska Medical Center. C57 Bl/6J mice (Jackson Labs \#000664) were used for excitability experiments. For optogenetic experiments, Chx10-cre;Ai32 (Litvina and Chen, 2017) mice were used, generated by crossing Chx10-cre/cre (Rowan and Cepko, 2004) (Chx10 BAC Jackson labs \#005105) mice with Ai32 (Madisen et al., 2012) reporter line (Jackson labs \#024109). Chx10-cre mice were a gift from Dr. Chinfei Chen (Harvard Medical School). In the resulting Chx10-Cre;Ai32 mice, channelrhodopsin is expressed in retinal ganglion cells and their axons, allowing us to optically stimulate them in brain slices (Litvina and Chen, 2017). Mice of both sexes were used for experiments and were raised in standard housing with standard feed and 12/12 h light/dark cycle.

\section{Enucleation}

We followed a previously described surgical procedure (Wilding et al., 2015) for bilateral enucleation with some minor modifications. 6-8 week-old mice were anesthetized with an intraperitoneal injection of ketamine $(100 \mathrm{mg} / \mathrm{kg})$ and xylazine $(10 \mathrm{mg} / \mathrm{kg})$. Once surgical level anesthesia was achieved (confirmed by the absence of toe-pinch and corneal reflexes), the eyes were swabbed with alternating swabs of betadine and $70 \%$ ethanol and one eye was enucleated with the help of fine ophthalmic surgical scissors. Cotton swabs were used to stop bleeding, and once hemostasis was achieved, the orbit was flushed with sterile saline, followed by bupivacaine $(0.5 \%)$ and was packed with Gelfoam. The eyelid margins were then trimmed using fine ophthalmic scissors and sutured closed with two to three simple interrupted stitches. The procedure was repeated for the other eye. After the surgery, the mice were injected with Rimadyl (5 mg/kg) subcutaneously and allowed to recover.

\section{Brain Slice Preparation}

For electrophysiology experiments, we prepared acute coronal brain slices at several time points after enucleation (2-4 days, 7-10 days, 14-16 days) for patch-clamp electrophysiology following the protected recovery method (Ting et al., 2014, 2018). Mice were euthanized with $\mathrm{CO}_{2}$ asphyxiation and cervical dislocation. The brain was immediately dissected and submerged in a frozen slurry of artificial cerebrospinal fluid (ACSF; $124 \mathrm{mM} \mathrm{NaCl}, 2.5 \mathrm{mM} \mathrm{KCl}, 1.25 \mathrm{mM} \mathrm{NaH}_{2} \mathrm{PO}_{4}, 24 \mathrm{mM} \mathrm{NaHCO} 3,12.5 \mathrm{mM}$ glucose, $2 \mathrm{mM} \mathrm{CaCl}_{2}, 2 \mathrm{mM} \mathrm{MgSO}_{4}$ ) and allowed to chill for approximately 1 minute. The cerebellum was removed, and the brain was mounted onto the specimen holder. We used a vibratome (Leica VT1000S) to cut $250 \mu \mathrm{m}$ thick coronal sections in ACSF continuously bubbling with a mixture of 5\% $\mathrm{CO}_{2}$ and $95 \% \mathrm{O}_{2}$. We confirmed and selected slices with dLGN with the help of a dissecting microscope. 
The slices were hemisected along the midline and transferred to a beaker containing N-Methyl-Dglucamine diatrizoate-ACSF (NMDG-ACSF; $92 \mathrm{mM} \mathrm{NMDG}, 2.5 \mathrm{mM} \mathrm{KCl}, 1.25 \mathrm{mM} \mathrm{NaH} \mathrm{PO}_{4} 30 \mathrm{mM}$ $\mathrm{NaHCO}_{3}, 20 \mathrm{mM}$ HEPES, $0.5 \mathrm{mM} \mathrm{CaCl}_{2}, 10 \mathrm{mM} \mathrm{MgSO}_{4}, 2 \mathrm{mM}$ thiourea, $5 \mathrm{mM}$ L-ascorbic acid, and 3 $\mathrm{mM}$ Na-pyruvate) warmed to approximately $30^{\circ} \mathrm{C}$ and bubbled with $5 \% \mathrm{O}_{2}$ and $95 \% \mathrm{CO}_{2}$. After 10-15 minutes, we transferred and allowed the slices to recover for one hour in a beaker containing room temperature ACSF before beginning patch-clamp recording. All materials and reagents were purchased from Thermo Fisher Scientific (Waltham, MA) unless otherwise noted.

\section{Electrophysiology}

After one hour of recovery in ACSF, we transferred the slices to a recording chamber placed on an upright microscope fitted with an electrophysiology setup (Scientifica, Uckfield, UK or Olympus BX51WI). We targeted dLGN neurons under IR illumination for whole-cell patch-clamp recording using pipettes pulled from thin wall borosilicate capillary tubes with an internal filament. The pipettes $(\mathrm{OD}=$ $1.2 \mathrm{~mm}, \mathrm{ID}=0.9 \mathrm{~mm}$ ) were pulled using a Sutter Instrument pipette puller (Sutter Instrument P-1000, Novato, CA) and had a resistance of 7-8 M $\Omega$. Signals were visualized on a digital oscilloscope (Rigol DS1102E, Rigol USA, Beaverton, OR). Current clamp and voltage clamp recordings were obtained using Clampex 10.6 software (Molecular Devices, San Jose, CA), Multiclamp 700B amplifier (Molecular Devices) and a Digidata 1550B digitizer (Molecular Devices). Electrophysiological recordings were obtained at room temperature.

Spiking behavior and miniature excitatory post-synaptic current (mEPSCs) were recorded from the dLGN of C57 mice. We used potassium-based pipette solution (120 K-gluconate, $8 \mathrm{KCl}, 2 \mathrm{EGTA}, 10$ HEPES, 5 ATP-Mg, 0.5 GTP-Na2, 5 phosphocreatine-Na2, $100 \mu \mathrm{M}$ CF568 hydrazide dye (Sigma Aldrich, St. Louis, MO), and 1-2\% Neurobiotin (Vector Labs, Burlingame, CA)) for these recordings. Reported voltages are corrected for liquid junction potential of $14 \mathrm{mV}$. mEPSCs were recorded in voltage-clamp configuration while holding the cells at $-74 \mathrm{mV}$. Once mEPSCs were recorded, we switched to current-clamp configuration and recorded cell responses to hyperpolarizing (-20 to $-260 \mathrm{pA})$ and depolarizing $(+20$ to $+260 \mathrm{pA})$ current injections.

We calculated the mean frequency and amplitude for mEPSCs using MiniAnalysis (Synaptosoft, Fort Lee, NJ). Input resistance was calculated using the current-voltage relationship (voltage response to a $-20 \mathrm{pA}$ current injection) and resting membrane potential was obtained as an average measurement of baseline membrane potential in current-clamp without any stimulus.

For optogenetics experiments, we used Chx10-cre;Ai32 mice (channelrhodopsin expression in retinal ganglion cell (RGC) axons in the dLGN). All data were recorded in voltage clamp configuration and the intracellular solution used for the experiments was Cesium-based (120 mM Cs-methanesulfonate, 
2 mM EGTA, 10 mM HEPES, 8 mM TEA-Cl, 5 mM ATP-Mg, 0.5 mM GTP-Na 2,5 mM

phosphocreatine- $\mathrm{Na}_{2}, 2 \mathrm{mM}$ QX-314). Brain slices were prepared as described above. Reported voltages for this intracellular solution are corrected for a $10 \mathrm{mV}$ liquid junction potential. The ACSF was supplemented with $60 \mu \mathrm{M}$ picrotoxin. Once we broke into the cells, we recorded AMPAR ( $\alpha$-amino-3hydroxy-5-methyl-4-isoxazolepropionic acid receptor)- and NMDAR (N-methyl-D-aspartate receptor)mediated synaptic currents (EPSC $\mathrm{AMPA}_{\mathrm{A}}$ and $\mathrm{EPSC}_{\mathrm{NMDA}}$ ) in response to a $460 \mathrm{~nm}$ LED stimulus while holding the cells at $-70 \mathrm{mV}$ and $+40 \mathrm{mV}$, respectively. Paired pulse experiments were performed in the presence of bath-applied $\gamma$-DGG $(\gamma$-D-glutamylglycine, $200 \mu \mathrm{M})$ and CTZ (cyclothiazide, $100 \mu \mathrm{M}$ ). Current responses to paired pulses of the LED stimulus were recorded at varying interval between pulses (100 ms, $200 \mathrm{~ms}, 500 \mathrm{~ms}$ and $1000 \mathrm{~ms}$ pulse interval) while holding the cell at $-70 \mathrm{mV}$. For release probability (Pr) measurement, we utilized a high frequency LED stimulus (10 Hz pulse train).

The AMPA/NMDA ratio was measured as the ratio of $\mathrm{EPSC}_{\mathrm{AMPA}}$ to the $\mathrm{EPSC}_{\mathrm{NMDA}}$. $\mathrm{EPSC}_{\mathrm{NMDA}}$ mediated current was measured after $20 \mathrm{~ms}$ of initial stimulus to minimize contamination with $\mathrm{EPSC}_{\mathrm{AMPA}}$. Paired pulse ratio was measured as the ratio of the second EPSC to the first EPSC (EPSC2/EPSC1). For Pr measurement, the cumulative amplitude of the responses to the $15^{\text {th }}$ to $30^{\text {th }}$ pulse fit with a straight line and extrapolated to the $\mathrm{Y}$-axis. The ratio of the first EPSC to the $\mathrm{Y}$-intercept of the fit provides $\operatorname{Pr}$ (Sakaba et al., 2002). The slope of the fit provides an estimation of the vesicle replenishment rate.

Single cell fills

For single cell fills, we loaded the cells with neurobiotin and CF568 dye via passive diffusion during recording. Following electrophysiology, the slices were immediately fixed in 4\% PFA for $\sim 1$ day at $4^{\circ} \mathrm{C}$. Following fixation, the slices were washed with $1 \mathrm{X}$ PBS and incubated with streptavidin conjugated with Alexa fluor $568(1 \mu \mathrm{g} / \mathrm{ml})$ in permeabilization buffer containing PBS, $0.5 \%$ DMSO, and $1 \%$ Triton $\mathrm{X}-100$ ( $\mathrm{pH}$ adjusted to 7.4 with $\mathrm{NaOH}$ ) for $>3$ days at $4^{\circ} \mathrm{C}$. The slices were then washed with 1X PBS six times, mounted, and coverslipped on Superfrost plus slides with VectaShield hardset (Vectorlabs \#H-1400-10) mounting medium.

\section{Immunohistochemistry}

For immunohistochemistry, C57 mice with appropriate treatment (control or enucleated) were euthanized with $\mathrm{CO}_{2}$ asphyxiation and cervical dislocation. Brains were immediately dissected, washed briefly in PBS and fixed in 4\% PFA. Fixed brains were cryoprotected in 30\% sucrose and embedded in $3 \%$ agar. $50 \mu \mathrm{m}$ coronal brain slices of the dLGN were obtained using a vibratome, collected immediately on SuperFrost Plus slides and stored at $-20^{\circ} \mathrm{C}$. The slides were washed in $1 \mathrm{X}$ PBS followed by blocking and permeabilization for 2 hours in blocking buffer (1800 $\mu \mathrm{l}$ X PBS, $0.5 \%$ Triton X-100, 5.5\% donkey 
serum, $\mathrm{pH} \sim 7.4)$. The slides were then incubated in 1:250 dilution of antibody solution in blocking buffer (Rabbit anti-vGlut2, Cedarlanelabs \#135403) for 2-4 days. Following incubation with primary antibody, the slices were washed in PBS, blocked for 2 hours and incubated with secondary antibodies (1:200, Donkey anti-Rabbit IgG, Alexa Fluor 568, Invitrogen \# A-10042), washed and mounted in Vectashield Hardset mounting medium and stored at $4{ }^{\circ} \mathrm{C}$ until imaged.

\section{Imaging and Analysis}

Single cell fills were imaged on a 2-photon setup (Scientifica) equipped with a Ti-Sapphire laser (Spectra-Physics, Santa Clara, CA) tuned to $800 \mathrm{~nm}$. Four images per plane were acquired with $1 \mu \mathrm{m}$ spacing between each plane. The dendritic arbors were traced in ImageJ(Schindelin et al., 2012) with the help of Simple Neurite Tracer plugin(Longair et al., 2011). Sholl analysis was performed using the Sholl analysis plugin(Ferreira et al., 2014) for ImageJ.

For vGlut2 imaging and analysis, images were acquired with the same setup as described above. Four images per plane were acquired with $0.3 \mu \mathrm{m}$ spacing between each plane (Imaging parameters: laser power at $\sim 75-85 \mu \mathrm{W}$, scale: $2.0757 \mathrm{px} / \mu \mathrm{m}$ ). Grouped average projection was obtained for all the images with a group size of 4 . Image slices were selected and were restacked to 6 images per slide such that the plane separation in the z-axis was $1.5 \mu \mathrm{m}$, converted to 8-bit images, thresholded, and converted to RGB images. The RGB images were analyzed using particle analyzer plugin in ImageJ to detect and quantify the vGlut2 (parameters: particle size $=4-200 \mu \mathrm{m}^{2}$ ), and the results were used to calculate the density per $1000 \mu \mathrm{m}^{2}$, and the average size of vGlut2 puncta $\left(\mu \mathrm{m}^{2}\right)$.

\section{Statistics}

Unless otherwise noted, data are presented as mean \pm SEM. Statistical significance was measured using Brown and Forsythe and Welch ANOVA test with Dunnett's T3 multiple comparison test, and unpaired Student's t-test $(\mathrm{p}<0.05)$ where applicable. For cumulative distribution analysis, statistical significance was measured using Komolgorov-Smirnov (K-S) test. Graphpad Prism, Microsoft Excel and Clampfit were used to perform all analysis. 


\section{$\underline{\text { Results }}$}

To evaluate the effects of traumatic optic nerve injury in the mature dLGN, we bilaterally enucleated adult mice and probed for changes in physiology and structure of the ganglion cell axon terminals as well as TC neurons. Our goal was to determine the time-dependent effects of severe injury at the retinogeniculate synapse, the rate and the extent of synaptic dysfunction, and responses of postsynaptic TC neurons to a relatively sudden and drastic loss of synaptic partners. Our findings demonstrate that following such injury, presynaptic dysfunction proceeds in a rapid manner in the retinorecipient region of the thalamus and compensatory mechanisms initiate in response, altering the physiology of the postsynaptic TC neurons in the dLGN.

\section{Optic tract degeneration starts early following severe injury to the optic nerve}

Our first goal was to determine the time course of RGC axon terminal degeneration in the dLGN following enucleation. To accomplish this, we obtained $50 \mu \mathrm{m}$ thick histological sections of the dLGN at 3 days, 7 days, and 14 days post-enucleation and stained them for the retinal axon terminal marker vGlut2. We utilized a semi-automated analysis to detect and quantify the presynaptic marker in images obtained from vGlut2 stained dLGN slices. Our analysis revealed that the density (Figure 1C, puncta/ $1000 \mu \mathrm{m}^{2}$ ) and size of vGlut2 puncta were significantly reduced at 7 days and later following enucleation (Figure 1D and E). There were no differences when we compared the punctum density between control $\left(3.693 \pm 0.604\right.$ puncta/ $\left.1000 \mu \mathrm{m}^{2}, \mathrm{n}=4\right)$ and injured animals at 3 days $(5.164 \pm 0.625$ puncta $\left./ 1000 \mu \mathrm{m}^{2}, \mathrm{n}=3, \mathrm{p}=0.349\right)$. We observed a significant reduction in punctum density at 7 days following enucleation $\left(0.951 \pm 0.084\right.$ puncta/ $\left.1000 \mu \mathrm{m}^{2}, \mathrm{n}=3, \mathrm{p}=0.048\right)$ and by 14 days vGlut 2 stained puncta were almost gone $\left(0.082 \pm 0.045\right.$ puncta $\left./ 1000 \mu \mathrm{m}^{2}, \mathrm{n}=3, \mathrm{p}=0.022\right)$. Further analysis revealed that there was a significant reduction in the punctum size $\left(\mu \mathrm{m}^{2}\right)$ at day $14\left(6.235 \pm 0.277 \mu \mathrm{m}^{2}, \mathrm{n}=3, \mathrm{p}=\right.$ $0.045)$ while no changes were observed at 3 days $\left(18.72 \pm 1.987 \mu \mathrm{m}^{2}, \mathrm{n}=3, \mathrm{p}=0.509\right)$ and 7 days $\left(9.042 \pm 0.160 \mu \mathrm{m}^{2}, \mathrm{n}=3, \mathrm{p}=0.116\right)$ compared to the control animals $\left(15.04 \pm 1.888 \mu \mathrm{m}^{2}, \mathrm{n}=4\right)$. Likewise, cumulative distribution analysis of the punctum size revealed that there was a progressive increase in the relative proportion of smaller vGlut2 labelled puncta at all time points after enucleation $(\mathrm{p}$ $=0.0021$ at 3 days, $\mathrm{p}<0.0001$ at 7 days, and $\mathrm{p}<0.0001$ at 14 days; K-S test). These data indicate that enucleation is followed by a gradual atrophy and loss of vGlut2 positive RGC synaptic terminals in the dLGN. 
A

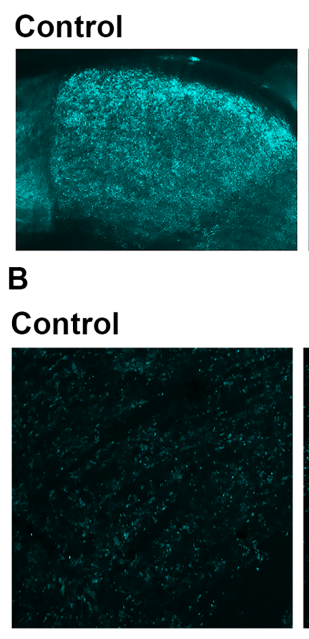

C

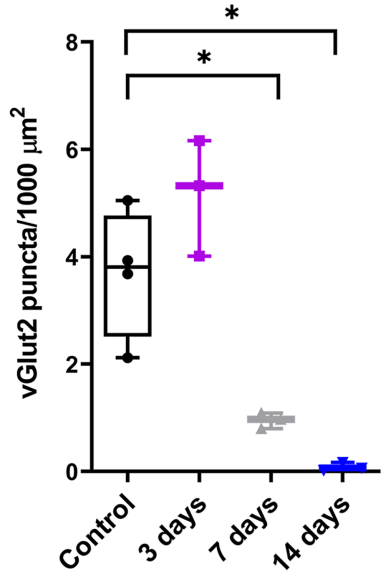

3 days

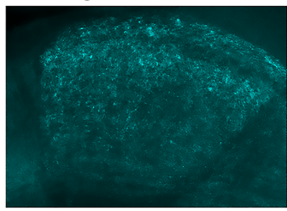

3 days

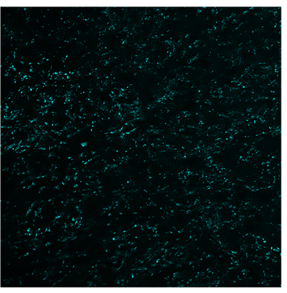

D

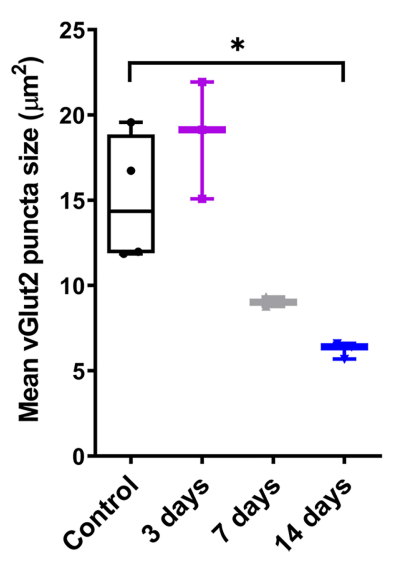

7 days

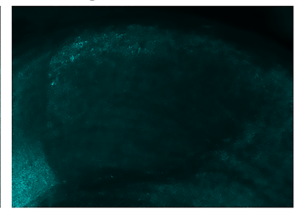

7 days

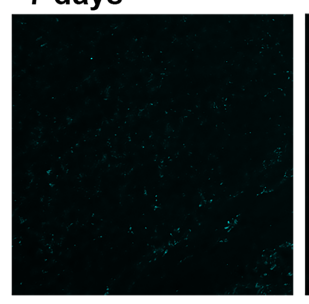

E
14 days

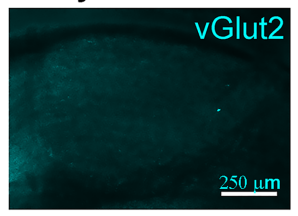

14 days

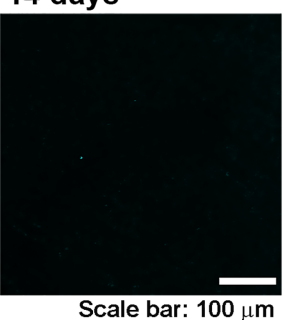

Scale bar: $100 \mu \mathrm{m}$

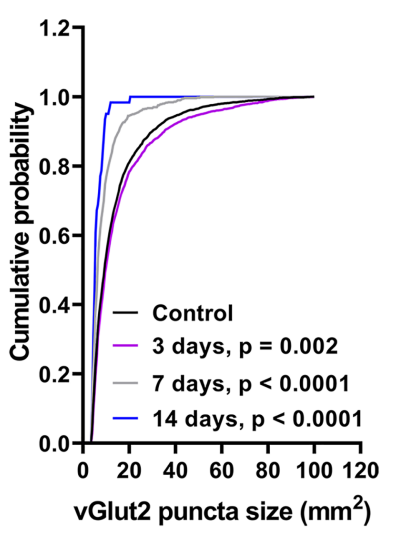

Figure 1. Loss of vGlut2 positive RGC terminals in the dLGN following enucleation. A)

Epifluorescence images of dLGN in C57 mice stained for vGlut2. B) Representative 2-photon images of vGlut2 puncta in the dLGN. C) There was a significant reduction in vGlut2 puncta density at 7-days ( $\mathrm{p}=$ $0.048, \mathrm{n}=3)$ and by 14 -days it was almost absent, $(\mathrm{p}=0.022, \mathrm{n}=3)$ following bilateral enucleation. D) The average size of vGlut2 puncta was reduced significantly at 14 -days post-enucleation $(p=0.045)$. E) Increase in the proportion of smaller puncta was observed when we performed a cumulative distribution analysis at 7-days ( $\mathrm{p}<0.0001, \mathrm{~K}-\mathrm{S}$ test) and 14-days ( $\mathrm{p}<0.0001, \mathrm{~K}-\mathrm{S}$ test) relative to the controls. 


\section{Enucleation triggers progressive loss of retinogeniculate synaptic function}

Our next set of experiments sought to determine how and over what time-course enucleation altered the function of synaptic inputs to dLGN TC neurons. To accomplish this, we first recorded miniature excitatory post synaptic currents (mEPSCs) from TC neurons of unoperated controls and enucleated animals. Surprisingly, we found only a modest difference in the mEPSC frequency following enucleation (Table 1, Figure 2B). While the comparison of the average mEPSC frequency did not reveal any significant differences between the control and enucleated group, comparison of the cumulative distribution of individual mEPSC inter-event intervals revealed a subtle shift to longer inter-event intervals at 7-10 days and 14-16 days post enucleation (Figure 2C). We next analyzed mEPSC amplitude, finding that there was no significant difference in the mean mEPSC amplitude of each recorded cell when we compared enucleated with the control animals (Figure 2E). However, there was a shift in the distribution of mEPSC amplitude histogram at 7-10 days, showing an increase in the proportion of events with larger amplitude (Figure $2 \mathrm{~F}$ ).

We also analyzed mEPSC decay kinetics, finding that while the means did not significantly differ between control and enucleation groups, there was significant shift in the cumulative distribution toward slower time constants (Figure 2I\&J). A previous study of plasticity in the dLGN has shown that monocular deprivation leads to an increase of mEPSC frequency due to strengthened inputs from corticothalamic projections, as evidenced by slower mEPSC kinetics due to dendritic filtering from their more distal input sites (Krahe and Guido, 2011). The shift in the distribution to slower mEPSC decay times in our experiments would point to a similar phenomenon occurring following enucleation. 


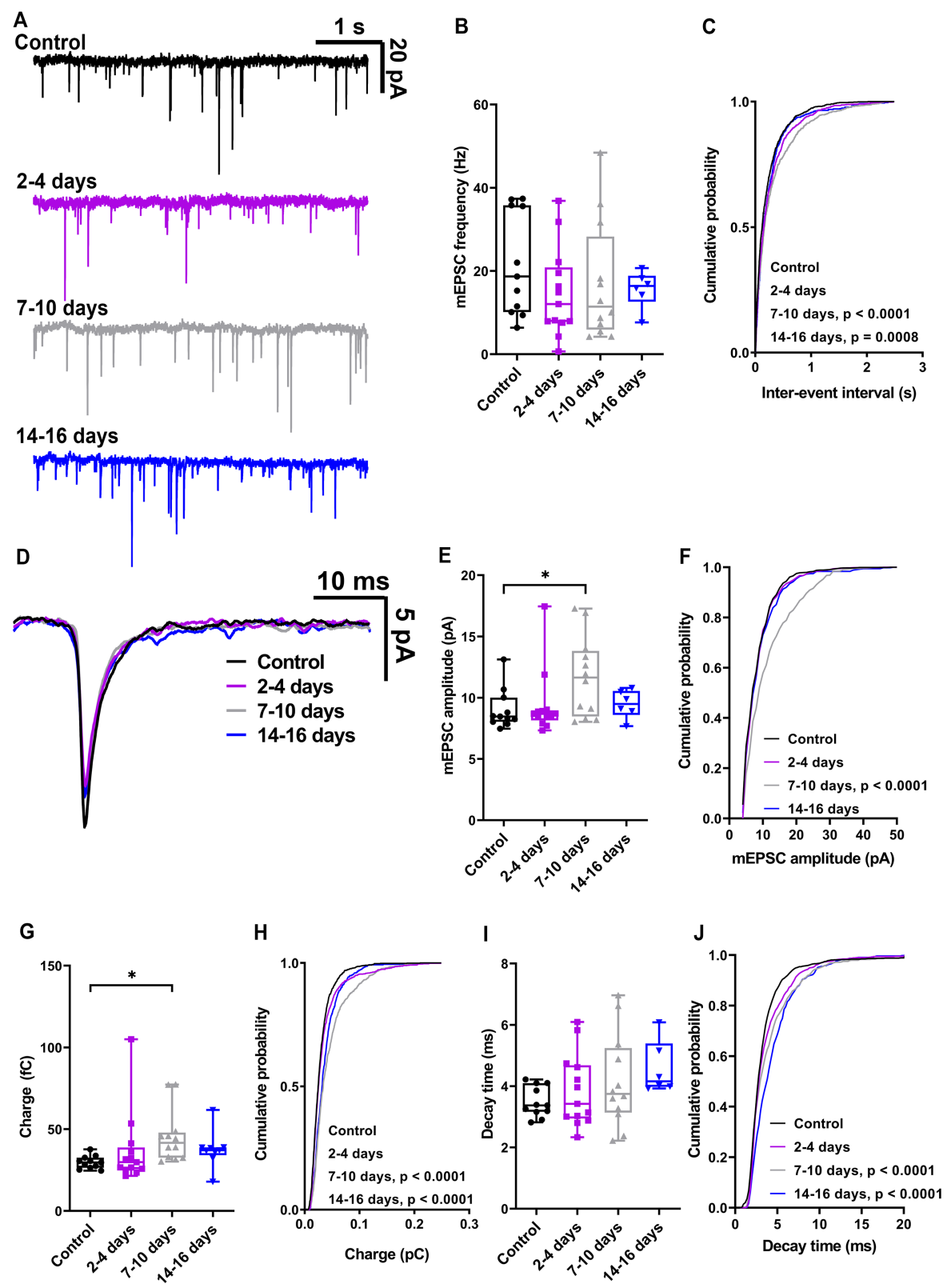

Figure 2. Bilateral enucleation alters synaptic input to TC neurons in the dLGN. A) Representative traces of mEPSCs recorded from the $\mathrm{dLGN}$ in control and enucleated animals. B) mEPSC frequency was not significantly altered following bilateral enucleation. C) Cumulative distribution analysis revealed that there was an increase in the proportion of events with longer inter-event intervals at 7-10-days ( $p<$ $0.0001, \mathrm{n}=12)$ and 14-16-days $(\mathrm{p}=0.0008, \mathrm{n}=6)$ post-enucleation relative to unoperated control animals $(\mathrm{n}=11)$. D) Representative traces of average mEPSCs. E and F) Amplitude of mEPSCs was reduced at 7-10 days following enucleation (E) shown by comparison of average amplitudes $(\mathrm{p}=0.040, \mathrm{n}$ $=12)$ as well as cumulative distribution analysis $(\mathrm{F} ; \mathrm{p}<0.0001)$. $\mathrm{G}$ and $\mathrm{H})$ Bilateral enucleation reduced the average area $(\mathrm{G})$ of $\mathrm{mEPSC}$ events at 7-10-days post enucleation $(\mathrm{p}=0.021)$. Cumulative distribution 
analysis (H) also showed that there was an overall increase in the number of events with larger area at 710-days ( $\mathrm{p}<0.0001)$ and 14-16-days ( $<<0.0001)$. I and J) Although there was no change in the average decay kinetics of mEPSCs in the enucleated cohort (I), there was an increase in the relative proportion of slower events $(\mathrm{J})$ at $7-10$-days $(\mathrm{p}<0.0001, \mathrm{~K}-\mathrm{S}$ test) and 14-16-days $(\mathrm{p}<0.0001, \mathrm{~K}-\mathrm{S}$ test).

The changes in mESPC frequency might be reflective of altered synaptic vesicle release properties at the retinogeniculate synapses. To test this possibility, we next measured evoked EPSCs from TC neurons using the Chx10-Cre;Ai32 mice in which channelrhodopsin is expressed in the retinal ganglion cell axons in the dLGN, allowing for activation of RGC axons in acute brain slices using light $(460 \mathrm{~nm})$. In these experiments, evoked EPSCs were detectable, but reduced in amplitude by 2 days following enucleation (Figure 3B and C). At the 7- and 14-days post-enucleation time points, however, we did not detect any EPSCs in response to optogenetic stimulation (Figure 3A and B). This is consistent with the observed loss of vGlut2-labeled puncta in the dLGN.

In the course of doing these experiments, we recorded and measured NMDA-receptor EPSCs $\left(\mathrm{EPSC}_{\mathrm{NMDA}}\right)$ in control and 2-days post-enucleation from brain slices and normalized the $\mathrm{EPSC}_{\mathrm{AMPA}}$ to the

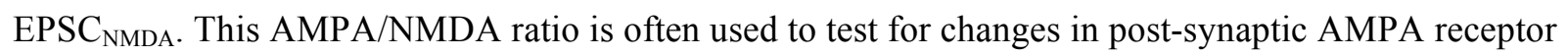
number and properties and is known to change at retinogeniculate synapses during development and in response to different light exposure conditions during maturation. Consistent with our mEPSC data, which showed no changes in mEPSC amplitude or kinetics 2-3 days post-enucleation, the AMPA/NMDA ratio was similar in control and 2-days post-enucleation slices $(2.649 \pm 0.295, \mathrm{n}=10$ for controls; $2.392 \pm$ $0.367 ; \mathrm{n}=7, \mathrm{p}=0.594$ for 2 days; Figure $3 \mathrm{E}$ ). These results suggest that there are no changes in the number or composition of the post-synaptic AMPARs at retinogeniculate synapses following enucleation. 


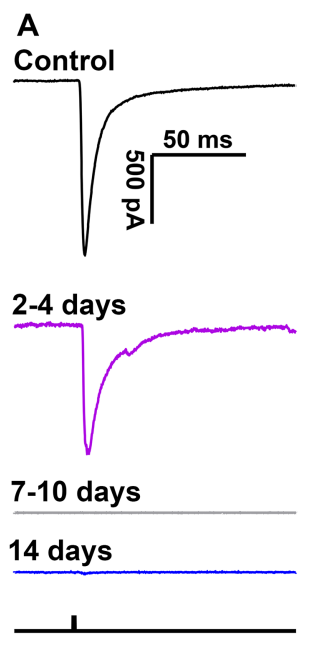

D

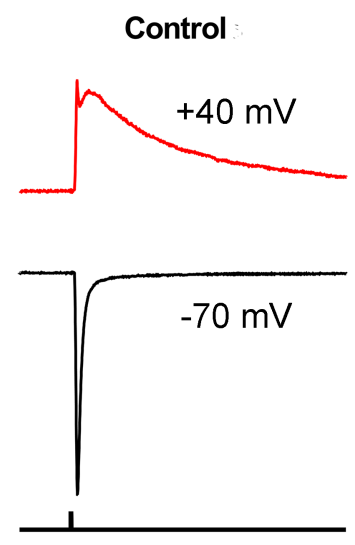

B

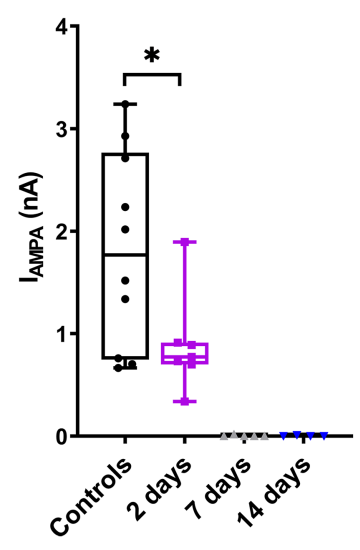

E

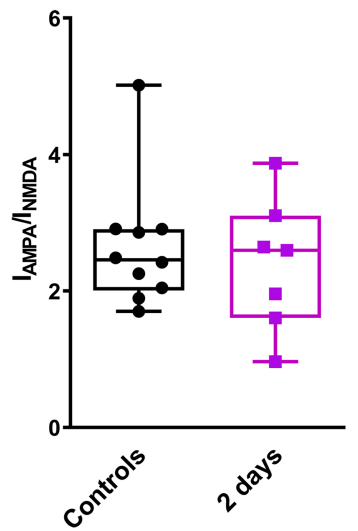

Figure 3. Enucleation induces progressive dysfunction at the retinogeniculate synapse. A)

Representative traces of EPSCs recorded from the TC neurons in response to optogenetic stimulation of RGC axons. B) AMPAR mediated EPSCs were reduced at 2-days $(\mathrm{p}=0.021, \mathrm{n}=7)$ following bilateral enucleation, while no response was detected at 7 and 14-days following enucleation. C) Similarly, there was a reduction in the amplitude of NMDAR mediated current at 2-days post enucleation $(\mathrm{p}=0.031)$. D) Examples of AMPAR and NMDAR mediated current response to optogenetic stimulation of RGC axons. E) The AMPA/NMDA ratio was similar in control and $2 \mathrm{~d}$ enucleated TC neurons.

In previous study from our lab, we demonstrated that ocular hypertension (OHT) brings about a significant increase in Pr in mice (Bhandari et al., 2019). Therefore, our next goal was to examine whether similar changes occur in presynaptic vesicle release probability $(\operatorname{Pr})$ in our model of severe injury to the optic nerve. As we noted above, alterations in mEPSC frequency could be a consequence of altered 
Pr. We used two different approaches to estimate Pr. In our first set of experiments, we measured EPSCs evoked by pairs of stimuli separated by varying inter-pulse intervals $(100 \mathrm{~ms}, 200 \mathrm{~ms}, 500 \mathrm{~ms}$, and 1000 $\mathrm{ms}$ ). The ratio of the second EPSC to the first EPSC (paired pulse ratio (PPR) = EPSC2/EPSC1) gives a relative measure of Pr. We did not detect any significant change in the PPR suggesting that the presynaptic vesicle release probability was not significantly altered at 2 days post-enucleation (Figure 4B).

\section{A}

\section{B}
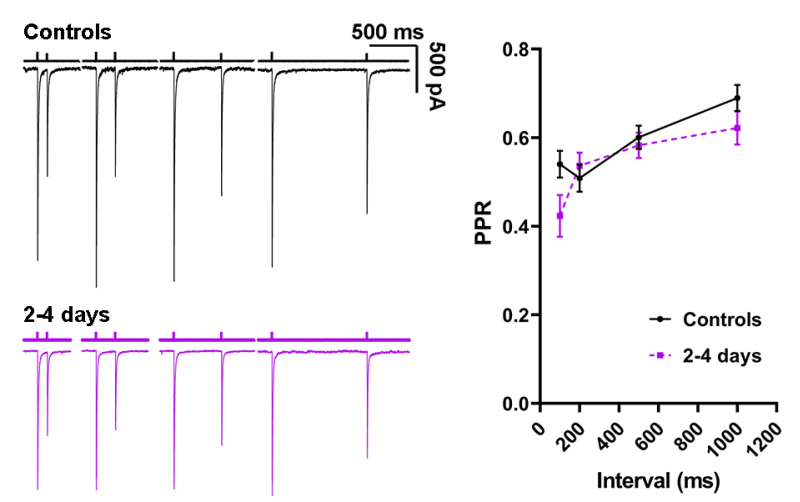

Figure 4. Bilateral enucleation does not affect the paired-pulse ratio at retinogeniculate synapses.

A) Example traces of EPSCs recorded in TC neurons in response to pairs of stimuli applied to stimulate the RGC axons spaced at different time intervals (100 ms, $200 \mathrm{~ms}, 500 \mathrm{~ms}$, and $1000 \mathrm{~ms})$. B) Plot of paired pulse ratio at different stimulus intervals. There was no significant difference at any time interval.

In a parallel approach, we used a $10 \mathrm{~Hz}$ train of stimuli to evoke EPSCs from TC neurons (Figure 5A). High-frequency stimulation induces a rapid release of vesicles from the presynaptic terminal leading to a state of equilibrium between the rate of vesicle replenishment and vesicle release. Subsequently, quantification of the amplitude of EPSCs evoked during high frequency stimulation and further analysis allows us to estimate Pr. To obtain a measure of release probability at the retinogeniculate synapse, we plotted the cumulative EPSC amplitude and fit the $15^{\text {th }}$ to the $30^{\text {th }}$ responses with a straight line (Figure 5B). The ratio of the first EPSC amplitude to the Y-intercept of the fit is Pr. Comparable to the results obtained from our PPR experiments, we could not detect any change in Pr between control $(0.50 \pm 0.03$; $\mathrm{n}$ $=12)$ and enucleated animals at 2 days post-enucleation $(0.46 \pm 0.03 ; \mathrm{n}=7, \mathrm{p}=0.36$; Figure $5 \mathrm{C})$. Consistent with the decline in EPSC amplitude and a loss of retinogeniculate synaptic input, the Yintercept was reduced in amplitude in these experiments (Figure 5D). These results demonstrate that 
bilateral enucleation does not trigger any detectable change in the presynaptic vesicle release probability within 2 days of injury.
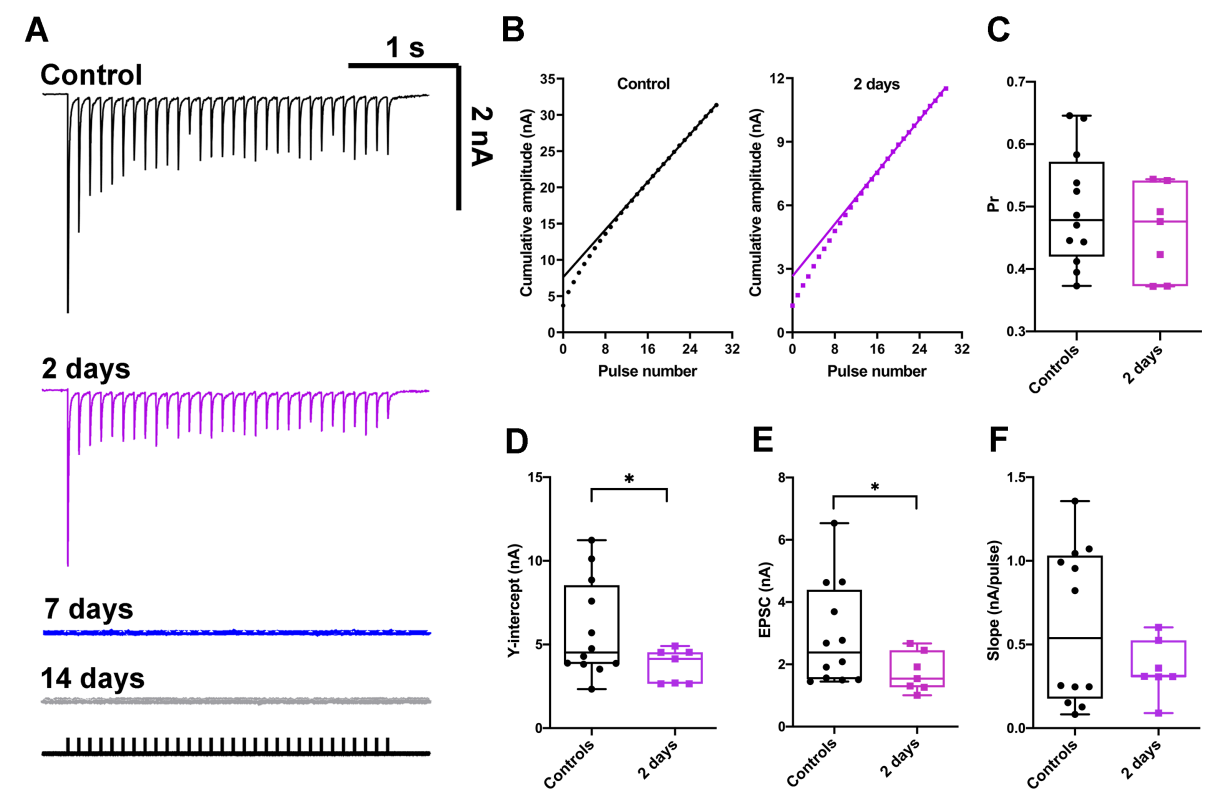

Figure 5. Presynaptic vesicle release at the retinogeniculate synapse does not change in response to

bilateral enucleation. A and B) Representative examples of current responses (A) of TC neurons to a 10 $\mathrm{Hz}$ stimulus at different time points following bilateral enucleation, plots of linear fit of $15^{\text {th }}$ to $30^{\text {th }}$ current response (B). There was no detectable response at 7- or 14-day time points C) No significant difference was observed in the presynaptic vesicle release probability between the control $(n=12)$ and the enucleated cohort at 2-days post enucleation $(n=7, p=0.36)$. D) There was a significant reduction in the $\mathrm{Y}$-intercept $(\mathrm{p}=0.038)$. E) Plot showing a reduction in the amplitude of the first EPSC at 2-days following enucleation $(\mathrm{p}=0.041)$. F) There was no significant difference in the relative vesicle replenishment rate at 2-days post enucleation $(p=0.11)$, estimated as the slope of the fit at the retinogeniculate synapse.

Bilateral enucleation increases the excitability of thalamocortical neurons in the $d L G N$

Having established that the synapse becomes dysfunctional within days following enucleation, we next sought to investigate the effects on TC neuron spike output, which might reflect homeostatic compensation in response to altered synaptic input. To accomplish this, we performed whole-cell currentclamp recordings from TC neurons in $250 \mu \mathrm{m}$ thick coronal brain slices from mice following enucleation. We utilized depolarizing and hyperpolarizing current injection steps to obtain spiking response and 
measure TC neuron passive membrane properties. We observed that TC neurons in the dLGN from enucleated animals were more excitable, as evidenced by an increase in action potential firing in response to depolarizing current stimuli (Table 2, Figure 6A-C). We quantified this by measuring both the halfmaximal current stimulus ( $\left.\mathrm{I}_{50}\right)$ and the area under the curve (AUC; nA*spikes) of the current-response plots. We found that the $\mathrm{I}_{50}$ showed a leftward shift and the AUC was increased following enucleation. This change was evident as early as 2-4 days post enucleation and at least until 14-16 days following enucleation. We next sought to probe the origin of the increased excitability by analyzing the resting membrane potential $\left(\mathrm{V}_{\text {rest }}\right)$ and the input resistance $\left(\mathrm{R}_{\text {in }}\right) . \mathrm{V}_{\text {rest }}$ was similar in control and enucleated animals at all time points (Figure $6 \mathrm{E}$ ). We detected a notable increase in the $\mathrm{R}_{\text {in }}$ at 2-4 days and 7-10 days post-enucleation while no significant change was observed at 14-16 days (Figure 6D). These results suggest that bilateral enucleation alters the membrane properties of cells in the dLGN along a biphasic time course.
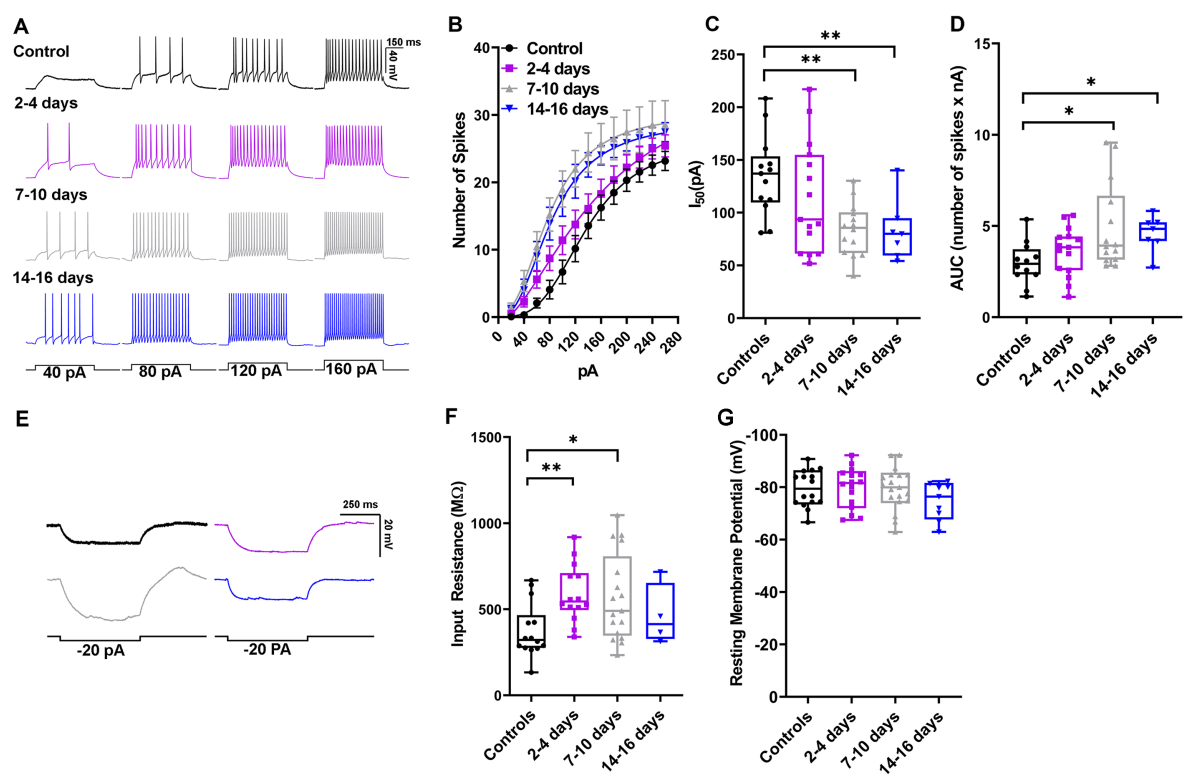

Figure 6. Bilateral enucleation increases the excitability of TC neurons. A) Whole-cell current-clamp recordings from TC neurons in response to depolarizing and hyperpolarizing current stimuli. B) Analysis of spiking data from TC neurons demonstrating enhanced excitability following enucleation. C\&D) Analysis of the half-maximal current $\left(\mathrm{I}_{50}\right)$ area under the curve (AUC). There was a significant reduction in the $\mathrm{I}_{50}$ at 7-10-days $(\mathrm{p}=0.002, \mathrm{n}=14)$ and 14-16-days $(\mathrm{p}=0.01, \mathrm{n}=7)$, and a significant increase in area under the curve at 7-10-days $(\mathrm{p}=0.033)$ and $14-16$-days $(\mathrm{p}=0.018)$ post enucleation. E) Voltage responses to hyperpolarizing current injections in control TC neurons (black) and 2d (purple), 7d (gray), and $14 \mathrm{~d}$ (blue) post-enucleation. F) Input resistance, measured using the voltage deflection to the $-20 \mathrm{pA}$ current stimulus, was increased at 2-4-days $(\mathrm{p}=0.045, \mathrm{n}=14)$ and 7 -10-days $(\mathrm{p}=0.044, \mathrm{n}=17)$ post- 
enucleation. G) Measurement of resting membrane potential $\left(\mathrm{V}_{\text {rest }}\right)$ from the TC neurons showed no significant change in the $\mathrm{V}_{\text {rest }}$ between the control animals and the enucleated cohort.

\section{Altered dendritic structure in cells from enucleated animals}

Optic nerve degeneration in glaucoma has been reported to alter the dendritic structure of dLGN relay neurons in primate and rodents (Gupta et al., 2007; Liu et al., 2014; Bhandari et al., 2019). Therefore, in a complementary set of experiments, we tested whether enucleation would trigger comparable post-synaptic dendritic changes. In this analysis, we examined single cell morphology and dendritic structure of TC neurons to evaluate enucleation-induced changes. The cells were filled with neurobiotin during electrophysiology recordings, processed with Alexa Fluor-conjugated streptavidin, and imaged later on a 2-photon imaging setup. Sholl analysis of the dendritic arbor pointed to a progressive pruning of TC neuron dendrites following enucleation. There were no significant differences in dendritic structure between controls and enucleated animals at 2-4 days following enucleation. By 7-10 days, however, there was a subtle reduction in the number of dendritic intersections with the Sholl rings between 115-125 $\mu \mathrm{m}$ from the cell body. By 14 -16 days post enucleation, dendritic fields were dramatically less complex. This reduction in dendritic complexity was more pronounced at the proximal portion of the dendritic structure relative to the soma. The reduction in dendritic complexity proximal to the soma could be represented by plotting the area under the curve (AUC) for the dendritic structure 35$105 \mu \mathrm{m}$ away from the somata (Figures 7B, C and D). In contrast, there appeared to be a slight increase in dendritic complexity distal to the soma at 14 days post-enucleation. Analysis of the total dendritic length in the same set of images revealed no significant changes, $(6555 \pm 617.5 \mu \mathrm{m}, \mathrm{n}=12$ for controls, $7136 \pm$ $1061 \mu \mathrm{m}, \mathrm{n}=7, \mathrm{p}=0.646$ for $2-4$ days, $6144 \pm 508.8, \mathrm{n}=5, \mathrm{p}=0.616$ for $7-10$ days, and $5618 \pm 512.8, \mathrm{n}$ $=9, \mathrm{p}=0.269$ for 14-16 days; Figure 7E). 


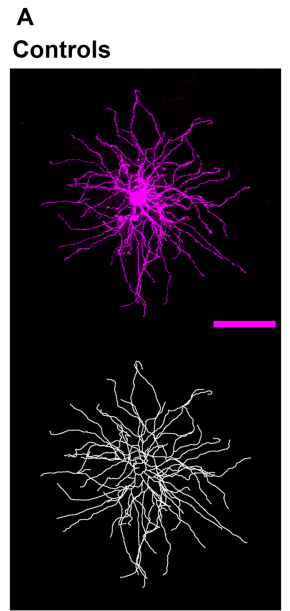

B

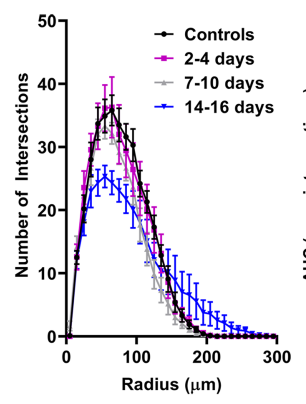

2-4 days

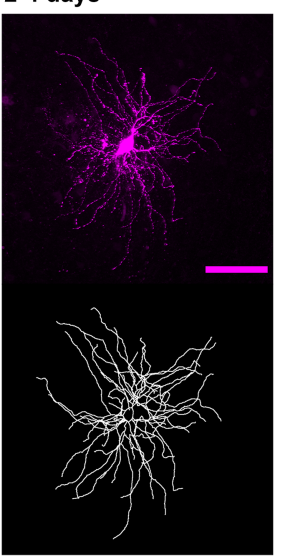

C

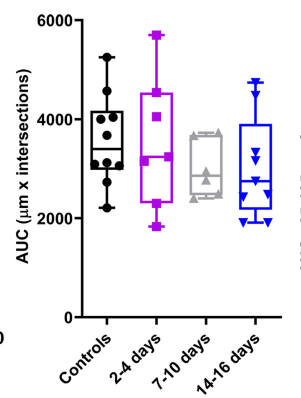

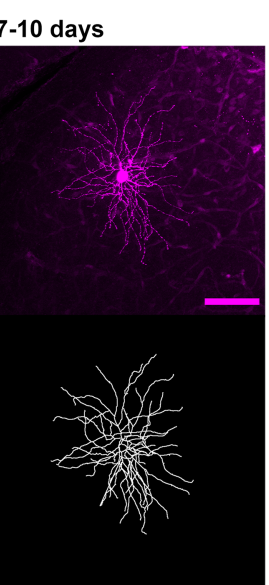

D

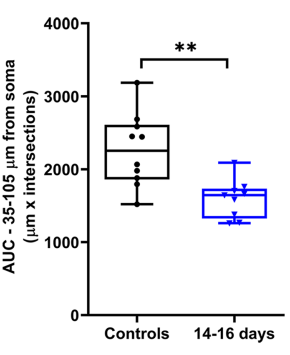

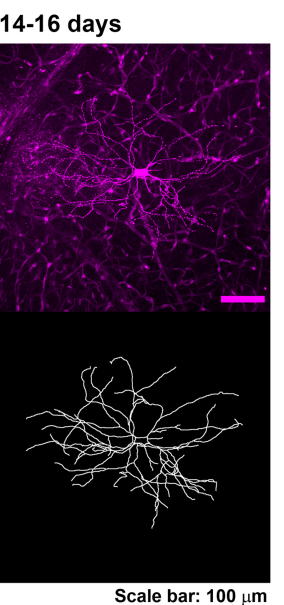

E

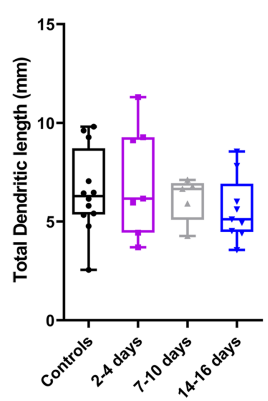

Figure 7. Reduction in dendritic complexity of TC neurons following bilateral enucleation. A)

Examples of 2-photon images of Neurobiotin-filled TC neurons (upper panels) and respective skeletonized dendritic structure (lower panels) from control animals and enucleated cohort. B, C and D) Sholl analysis (B) of the dendritic structure revealed that there was a reduction in the dendritic complexity of TC neurons from enucleated mice at 14-16 days post enucleation. Analysis of area under the curve obtained from the Sholl plot did not reveal any differences between the dendritic structure (C). However, when the area under the curve for the dendritic structure between $35-105 \mu \mathrm{m}$ away from the TC neuron somata (D), there was a pronounced decrease in the dendritic complexity at $14-16$ days $(\mathrm{p}=0.003, \mathrm{n}=9)$ following enucleation when compared to the TC neurons from control animals $(n=10)$. E) There was no significant change in the total dendritic length of TC neurons in all animals. 


\section{$\underline{\text { Discussion }}$}

Neuronal activity is one of the most stable components of the nervous system and stability is required throughout life to maintain functional connectivity and activity. The balance in neuronal activity is the result of closely monitored processes that regulate network activity and adapt via compensatory mechanisms including change in synaptic properties, intrinsic excitability, and/or neuronal structure. Plasticity of synaptic transmission and neuronal excitability in the visual cortex in response to altered visual input offers a prime example of this phenomenon (Turrigiano et al., 1998; Turrigiano, 1999; Desai et al., 2002; Turrigiano and Nelson, 2004, 2004; Wallace and Bear, 2004; Wierenga et al., 2005; Maffei and Turrigiano, 2008; Turrigiano, 2012; Keck et al., 2013; Nahmani and Turrigiano, 2014a). Different experimental paradigms involving injury or visual deprivation have revealed that plasticity in the visual system extends to the thalamic partners as well (Bhandari et al., 2019; Krahe and Guido, 2011).

The primary goal of the current study was to test the hypothesis that injury to the optic nerve induces homeostatic plasticity in the mature dLGN. Our results demonstrate that in response to injury triggered by bilateral enucleation, dLGN TC neurons display both functional and structural plasticity, namely an increase in intrinsic excitability and a decrease in dendritic complexity. We observed that TC neurons from enucleated mice more readily fire action potentials in response to depolarizing current, implying that their output to the visual cortex is enhanced in response to injury. Hinting at an underlying mechanism, we found that enucleation led to an increase in TC neuron input resistance, potentially a result of slightly reduced synaptic input as well as the slight reduction in dendritic complexity, which is likely to contribute to enhanced excitability. Resting membrane potential was similar in TC neurons from control and enucleated mice, indicating that changes in spiking did not result from changes in proximity to spike threshold. Such enhancement of intrinsic excitability is consistent with a homeostatic scaling of neuronal responsiveness following perturbation of synaptic inputs carrying visual information from the retina.

Our immunofluorescence experiments revealed that by approximately one week post-enucleation, there was a reduction in vGlut2-stained RGC axon terminals and by 14 days they were almost entirely absent, suggesting that RGC terminals progressively degenerate following transection of the optic nerve. This is further supported by the absence of EPSCs in TC neurons in response to optogenetic stimulation of RGC axon terminals by 7 days post-enucleation. Glaucoma involves a more subtle axonal injury that results from damage and stress at the optic nerve head where RGC axons exit the eye. Several studies have reported that in glaucoma, axonal degeneration and transport failure proceed in a distal to proximal manner and axonal pathology precedes RGC somatic degeneration (Crish et al., 2010; Calkins and Horner, 2012; Smith et al., 2016). Thus, the earliest pathological signs in glaucoma may not be axon or RGC soma loss, but functional changes in neuronal communication. This has been observed in glaucoma 
models, where the density of retinal terminals in the brain remains largely unchanged until late in the disease process, but they show earlier signs of physiological and metabolic deficiency. These changes manifest as reduction in the size of mitochondria, reduction in trace metal levels, and reduction in the number and size of pre-synaptic active zones, suggesting physiological and metabolic deficiency and altered synaptic signaling (Crish et al., 2010; Smith et al., 2016). Enucleation is a much more rapid and extreme axonal injury than ocular hypertension, and might recapitulate some of the pathological events of glaucoma or other optic neuropathies, albeit on an accelerated time course.

Synaptic scaling via changes in post-synaptic receptor complement is common in homeostatic plasticity, including in cortical pyramidal neurons (Maffei and Turrigiano, 2008; Turrigiano, 2008; Gainey et al., 2009; Keck et al., 2013; Fernandes and Carvalho, 2016; Teichert et al., 2017; Chowdhury and Hell, 2018; Venkatesan et al., 2020). However, using optogenetic activation of RCG axons in acute dLGN slices, we did not observe any change in the amplitude of mEPSCs or $\mathrm{I}_{\mathrm{AMPA}} / \mathrm{I}_{\mathrm{NMDA}}$ indicating that there were no detectable changes in the number and/or composition of post-synaptic AMPARs following enucleation. Changes in AMPA/NMDA ratio in the dLGN have been previously reported during visual deprivation and dark rearing during development (Hooks and Chen, 2006; Louros et al., 2014). We did observe parallel reductions in the amplitude of $\mathrm{I}_{\mathrm{NMDA}}$ and $\mathrm{I}_{\mathrm{AMPAR}}$ after 2 days of enucleation. This suggests that the synapse is degenerating at that time point and there is reduced synaptic input to evoke stronger EPSCs. Alternately, as noted above, physiological, and metabolic deficiency in the optic nerve are present in a mouse glaucoma model and are accompanied by changes in RGC presynaptic active zones in the superior colliculus. If this were the case in the dLGN following enucleation, this could offer us an alternate explanation to the observed reduction in EPSC amplitudes.

Surprisingly, enucleation only had subtle effects on the mEPSC frequency measured in TC neurons despite the notable disappearance of vGlut2 puncta and loss of retinogeniculate synaptic function. This might suggest that the bulk of mEPSCs recorded from control mice are not of retinal origin but originate from synaptic inputs arising from other sources such as layer VI of visual cortex. An alternative possibility is that a substantial fraction of mEPSCs recorded in control TC neurons do arise from retinogeniculate sources, but the proportion from non-retinal inputs increases in parallel with the loss of RGC axon terminals and retinogeniculate synaptic function. If RGC synaptic inputs have entirely degenerated by 7 days post-enucleation, which is supported by our optogenetics experiments and vGlut 2 staining, this might imply that corticogeniculate inputs as well as other excitatory inputs from the superior colliculus and the brain stem (Guido, 2018) make a fairly substantial contribution to the background excitatory input to dLGN TC neurons at that time point. Alternatively, loss of retinogeniculate input might be accompanied by a parallel increase in synaptic strength at the corticothalamic synapses, possibly as an increase in Pr, vesicle pool size, or number of functional synaptic contacts. Future studies should 
explore whether and how severe optic nerve injury may alter the distribution and release of vesicles, and what are the influences of cortical feedback synapses to the dLGN in response to such stressors.

We previously demonstrated that during a modest and sustained ocular hypertension, a key risk factor for glaucoma, vesicle release probability in the retinogeniculate synapse was increased (Bhandari et al., 2019). Although the extent of injury to the optic nerve is more severe in the present study, our results here present an interesting contrast to results from ocular hypertension. We observed that the release probability remained unchanged after 2 days of enucleation. We could not probe for Pr changes at later time points since we were unable to evoke EPSCs at $7 \mathrm{~d}$ or $14 \mathrm{~d}$ post-enucleation. However, we can hypothesize that the physiological dysfunction observed in enucleation is much faster compared to OHT due to the extent of damage to the system as well as the type of damage. Another possibility could be that the results may be related to unaltered vGlut2 levels in the dLGN at 3-days post-enucleation. Vesicular glutamate transporters have been shown to be one of the many factors regulating $\operatorname{Pr}$ (Land et al., 2004; Körber and Kuner, 2016; Zhang et al., 2019) and unaltered vGlut2 numbers at 3-days post-enucleation could be one possible mechanism for the unaltered $\operatorname{Pr}$ in our experiments at 2-days post-enucleation.

One interesting feature of dLGN TC neurons synaptic anatomy is that inputs arising from the visual cortex are concentrated towards the dendrites distal to the somata while the synaptic inputs from the retina are concentrated towards the proximal dendrites (Sherman and Guillery, 2002; Krahe and Guido, 2011). This might suggest that the loss of synaptic input from the retina can lead to measurable changes in the dendritic structure. Changes in the dendritic component are fairly well-documented and occur during development and depend on retinal input (Vaughn et al., 1988; McAllister, 2000; CohenCory and Lom, 2004; Cline and Haas, 2008; Callaway and Borrell, 2011; El-Danaf et al., 2015). Additionally, we have shown that in ocular hypertension, dLGN TC neuron dendritic complexity is reduced, especially in regions proximal to the TC neuron somata, where they receive retinal inputs (Bhandari et al., 2019). Findings from the current experiments indicate that similarly, there is a reduction in dendritic complexity proximal to the TC neuron somata, and these changes are prominent and significant by 14 days post-enucleation. This supports the notion that dendritic pruning and reorganization, even by neurons that are not directly damaged, is a common feature of degenerative disease and nervous system injury.

In conclusion, we found that enucleation leads to structural and functional changes in the dLGN. On the pre-synaptic side, these include loss of RGC presynaptic terminals and synaptic input to the TC neurons without any detectable changes in vesicle release probability. Post-synaptically, we observed an increase in the input resistance of the TC neurons accompanied by an increase in the intrinsic excitability while no change in the post-synaptic membrane receptor composition and number was observed. This implies that TC neurons display certain features of homeostatic plasticity in response to degeneration of 
their major driver input and sheds light on mechanisms that might contribute to visual system plasticity in visual system diseases such as glaucoma or other optic neuropathies. This is important as plasticity mechanisms exist as stabilizing tools to modulate neuronal/synaptic function in response to any changes in the normal activity (increase or decrease), and while it has been extensively studied in the developing visual system (Gordon and Stryker, 1996; Desai et al., 2002; Turrigiano and Nelson, 2004; Hooks and Chen, 2006, 2008, 2008; Karmarkar and Dan, 2006; Turrigiano, 2008; Keck et al., 2013; Louros et al., 2014; Nahmani and Turrigiano, 2014b, 2014a) less is known about plasticity mechanisms operating in the adult. Our results provide an important groundwork on plasticity in the mature dLGN in response to optic nerve injury. 


\section{$\underline{\text { Acknowledgements: }}$}

We would like to thank Elizabeth Bierlein for comments on the manuscript. We are grateful to Dr. Chinfei Chen (Harvard Medical School) for supplying Chx10-Cre mice.

Author contributions: $\mathrm{AB}$ and $\mathrm{MVH}$ designed the experiments; $\mathrm{AB}$, JS, and $\mathrm{MVH}$ performed the

experiments; AB, JS, and MVH analyzed the data; $\mathrm{AB}$ and $\mathrm{MVH}$ wrote the manuscript and prepared figures; MVH acquired funding.

Declaration of interest: none.

Funding: This work was supported by National Institutes of Health (NIH/NEI R01 EY030507),

Brightfocus Foundation National Glaucoma Research Program (G2017027), University of Nebraska Collaboration Initiative Seed Grant, and Molecular Biology of Neurosensory Systems COBRE grant (NIH/NIGMS, P30 GM110768). 


\section{$\underline{\text { References }}$}

Abbott LF, Nelson SB (2000) Synaptic plasticity: taming the beast. Nat Neurosci 3:1178-1183.

Araújo SES, Mendonça HR, Wheeler NA, Campello-Costa P, Jacobs KM, Gomes FCA, Fox MA, Fuss B (2017) Inflammatory demyelination alters subcortical visual circuits. J Neuroinflammation 14 Available at: https://www.ncbi.nlm.nih.gov/pmc/articles/PMC5562979/ [Accessed August 4, 2020].

Beck H, Yaari Y (2008) Plasticity of intrinsic neuronal properties in CNS disorders. Nat Rev Neurosci 9:357-369.

Bhandari A, Smith JC, Zhang Y, Jensen AA, Reid L, Goeser T, Fan S, Ghate D, Van Hook MJ (2019) Early-Stage Ocular Hypertension Alters Retinal Ganglion Cell Synaptic Transmission in the Visual Thalamus. Front Cell Neurosci 13:426.

Bickford ME, Slusarczyk A, Dilger EK, Krahe TE, Kucuk C, Guido W (2010) Synaptic development of the mouse dorsal lateral geniculate nucleus. J Comp Neurol 518:622-635.

Bliss TVP, Collingridge GL, Morris RGM (2014) Synaptic plasticity in health and disease: introduction and overview. Philos Trans R Soc B Biol Sci 369 Available at: https://www.ncbi.nlm.nih.gov/pmc/articles/PMC3843863/ [Accessed February 20, 2020].

Calkins DJ, Horner PJ (2012) The Cell and Molecular Biology of Glaucoma: Axonopathy and the Brain. Invest Ophthalmol Vis Sci 53:2482-2484.

Callaway EM, Borrell V (2011) Developmental Sculpting of Dendritic Morphology of Layer 4 Neurons in Visual Cortex: Influence of Retinal Input. J Neurosci 31:7456-7470.

Chen C, Bickford ME, Hirsch JA (2016) Untangling the Web between Eye and Brain. Cell 165:20-21.

Chen C, Regehr WG (2000) Developmental Remodeling of the Retinogeniculate Synapse. Neuron 28:955-966.

Chowdhury D, Hell JW (2018) Homeostatic synaptic scaling: molecular regulators of synaptic AMPAtype glutamate receptors. F1000Research 7:234.

Cline H, Haas K (2008) The regulation of dendritic arbor development and plasticity by glutamatergic synaptic input: a review of the synaptotrophic hypothesis. J Physiol 586:1509-1517.

Cohen-Cory S, Lom B (2004) Neurotrophic regulation of retinal ganglion cell synaptic connectivity: from axons and dendrites to synapses. Int J Dev Biol 48:947-956.

Crish SD, Sappington RM, Inman DM, Horner PJ, Calkins DJ (2010) Distal axonopathy with structural persistence in glaucomatous neurodegeneration. Proc Natl Acad Sci 107:5196-5201.

D’Angelo E (2010) Homeostasis of intrinsic excitability: making the point. J Physiol 588:901-902. 
Darlington CL, Dutia MB, Smith PF (2002) The contribution of the intrinsic excitability of vestibular nucleus neurons to recovery from vestibular damage. Eur J Neurosci 15:1719-1727.

Desai NS, Cudmore RH, Nelson SB, Turrigiano GG (2002) Critical periods for experience-dependent synaptic scaling in visual cortex. Nat Neurosci 5:783-789.

El-Danaf RN, Krahe TE, Dilger EK, Bickford ME, Fox MA, Guido W (2015) Developmental remodeling of relay cells in the dorsal lateral geniculate nucleus in the absence of retinal input. Neural Develop 10 Available at: https://www.ncbi.nlm.nih.gov/pmc/articles/PMC4502538/ [Accessed February 24, 2020].

Fernandes D, Carvalho AL (2016) Mechanisms of homeostatic plasticity in the excitatory synapse. J Neurochem 139:973-996.

Ferreira TA, Blackman AV, Oyrer J, Jayabal S, Chung AJ, Watt AJ, Sjöström PJ, Meyel DJ van (2014) Neuronal morphometry directly from bitmap images. Nat Methods 11:982-984.

Gainey MA, Hurvitz-Wolff JR, Lambo ME, Turrigiano GG (2009) Synaptic Scaling Requires the GluR2 Subunit of the AMPA Receptor. J Neurosci 29:6479-6489.

Gonzalez D, Satriotomo I, Miki T, Lee K-Y, Yokoyama T, Touge T, Matsumoto Y, Li H-P, Kuriyama S, Takeuchi Y (2005) Effects of Monocular Enucleation on Calbindin-D 28k and c-Fos Expression in the Lateral Geniculate Nucleus in Rats. Okajimas Folia Anat Jpn 82:9-18.

Gordon JA, Stryker MP (1996) Experience-Dependent Plasticity of Binocular Responses in the Primary Visual Cortex of the Mouse. J Neurosci 16:3274-3286.

Guido W (2018) Development, form, and function of the mouse visual thalamus. J Neurophysiol 120:211-225.

Gupta N, Ly T, Zhang Q, Kaufman PL, Weinreb RN, Yücel YH (2007) Chronic ocular hypertension induces dendrite pathology in the lateral geniculate nucleus of the brain. Exp Eye Res 84:176184.

Hauser JL, Liu X, Litvina EY, Chen C (2014) Prolonged synaptic currents increase relay neuron firing at the developing retinogeniculate synapse. J Neurophysiol 112:1714-1728.

Hayakawa I, Kawasaki H (2010) Rearrangement of Retinogeniculate Projection Patterns after EyeSpecific Segregation in Mice Manzoni OJ, ed. PLoS ONE 5:e11001.

Hong YK, Chen C (2011) Wiring and rewiring of the retinogeniculate synapse. Curr Opin Neurobiol 21:228-237.

Hooks BM, Chen C (2006) Distinct Roles for Spontaneous and Visual Activity in Remodeling of the Retinogeniculate Synapse. Neuron 52:281-291.

Hooks BM, Chen C (2008) Vision Triggers an Experience-Dependent Sensitive Period at the Retinogeniculate Synapse. J Neurosci 28:4807-4817. 
Howland JG, Wang YT (2008) Chapter 8 Synaptic plasticity in learning and memory: Stress effects in the hippocampus. In: Progress in Brain Research (Sossin WS, Lacaille J-C, Castellucci VF, Belleville S, eds), pp 145-158 Essence of Memory. Elsevier. Available at: http://www.sciencedirect.com/science/article/pii/S0079612307000088 [Accessed February 20, 2020].

Jaepel J, Hübener M, Bonhoeffer T, Rose T (2017) Lateral geniculate neurons projecting to primary visual cortex show ocular dominance plasticity in adult mice. Nat Neurosci 20:1708-1714.

Karmarkar UR, Dan Y (2006) Experience-Dependent Plasticity in Adult Visual Cortex. Neuron 52:577585.

Keck T, Keller GB, Jacobsen RI, Eysel UT, Bonhoeffer T, Hübener M (2013) Synaptic Scaling and Homeostatic Plasticity in the Mouse Visual Cortex In Vivo. Neuron 80:327-334.

Körber C, Kuner T (2016) Molecular Machines Regulating the Release Probability of Synaptic Vesicles at the Active Zone. Front Synaptic Neurosci 8 Available at: https://www.ncbi.nlm.nih.gov/pmc/articles/PMC4773589/ [Accessed August 1, 2020].

Krahe TE, Guido W (2011) Homeostatic Plasticity in the Visual Thalamus by Monocular Deprivation. J Neurosci 31:6842-6849.

Krahe TE, Seabrook TA, Chen C-KJ, Fox MA, Guido W (2012) Modulation of CREB in the Dorsal Lateral Geniculate Nucleus of Dark-Reared Mice. Neural Plast 2012 Available at: https://www.ncbi.nlm.nih.gov/pmc/articles/PMC3265102/ [Accessed October 18, 2020].

Lambo ME, Turrigiano GG (2013) Synaptic and Intrinsic Homeostatic Mechanisms Cooperate to Increase L2/3 Pyramidal Neuron Excitability during a Late Phase of Critical Period Plasticity. J Neurosci 33:8810-8819.

Land PW, Kyonka E, Shamalla-Hannah L (2004) Vesicular glutamate transporters in the lateral geniculate nucleus: expression of VGLUT2 by retinal terminals. Brain Res 996:251-254.

Litvina EY, Chen C (2017) An evolving view of retinogeniculate transmission. Vis Neurosci 34:E013.

Liu M, Guo L, Salt TE, Cordeiro MF (2014) Dendritic Changes in Rat Visual Pathway Associated with Experimental Ocular Hypertension. Curr Eye Res 39:953-963.

Longair MH, Baker DA, Armstrong JD (2011) Simple Neurite Tracer: open source software for reconstruction, visualization and analysis of neuronal processes. Bioinformatics 27:2453-2454.

Louros SR, Hooks BM, Litvina L, Carvalho AL, Chen C (2014) A Role for Stargazin in ExperienceDependent Plasticity. Cell Rep 7:1614-1625.

Ly T, Gupta N, Weinreb RN, Kaufman PL, Yücel YH (2011) Dendrite Plasticity in the Lateral Geniculate Nucleus in Primate Glaucoma. Vision Res 51:243-250. 
Madisen L et al. (2012) A toolbox of Cre-dependent optogenetic transgenic mice for light-induced activation and silencing. Nat Neurosci 15:793-802.

Maffei A, Turrigiano GG (2008) Multiple Modes of Network Homeostasis in Visual Cortical Layer 2/3. J Neurosci 28:4377-4384.

Mazade R, Alonso JM (2017) Thalamocortical processing in vision. Vis Neurosci 34:E007.

McAllister AK (2000) Cellular and Molecular Mechanisms of Dendrite Growth. Cereb Cortex 10:963973.

Meriney SD, Fanselow EE (2019) Chapter 14 - Synaptic Plasticity. In: Synaptic Transmission (Meriney SD, Fanselow EE, eds), pp 287-329. Academic Press. Available at: http://www.sciencedirect.com/science/article/pii/B9780128153208000144 [Accessed February 20, 2020].

Monavarfeshani A, Sabbagh U, Fox MA (2017) Not a one-trick pony: Diverse connectivity and functions of the rodent lateral geniculate complex. Vis Neurosci 34:E012.

Nahmani M, Turrigiano GG (2014a) Adult cortical plasticity following injury: Recapitulation of critical period mechanisms? Neuroscience 283:4-16.

Nahmani M, Turrigiano GG (2014b) Adult cortical plasticity following injury: Recapitulation of critical period mechanisms? Neuroscience 283:4-16.

Pang J-J, Frankfort BJ, Gross RL, Wu SM (2015) Elevated intraocular pressure decreases response sensitivity of inner retinal neurons in experimental glaucoma mice. Proc Natl Acad Sci 112:25932598.

Rose T, Bonhoeffer T (2018) Experience-dependent plasticity in the lateral geniculate nucleus. Curr Opin Neurobiol 53:22-28.

Rowan S, Cepko CL (2004) Genetic analysis of the homeodomain transcription factor Chx10 in the retina using a novel multifunctional BAC transgenic mouse reporter. Dev Biol 271:388-402.

Sakaba T, Schneggenburger R, Neher E (2002) Estimation of quantal parameters at the calyx of Held synapse. Neurosci Res 44:343-356.

Schindelin J, Arganda-Carreras I, Frise E, Kaynig V, Longair M, Pietzsch T, Preibisch S, Rueden C, Saalfeld S, Schmid B, Tinevez J-Y, White DJ, Hartenstein V, Eliceiri K, Tomancak P, Cardona A (2012) Fiji: an open-source platform for biological-image analysis. Nat Methods 9:676-682.

Schulz DJ (2006) Plasticity and stability in neuronal output via changes in intrinsic excitability: it's what's inside that counts. J Exp Biol 209:4821-4827.

Sherman SM, Guillery RW (2002) The role of the thalamus in the flow of information to the cortex Adams P, Guillery RW, Sherman SM, Sillito AM, eds. Philos Trans R Soc Lond B Biol Sci 357:1695-1708. 
Smith MA, Xia CZ, Dengler-Crish CM, Fening KM, Inman DM, Schofield BR, Crish SD (2016)

Persistence of intact retinal ganglion cell terminals after axonal transport loss in the DBA/2J mouse model of glaucoma. J Comp Neurol 524:3503-3517.

Teichert M, Liebmann L, Hübner CA, Bolz J (2017) Homeostatic plasticity and synaptic scaling in the adult mouse auditory cortex. Sci Rep 7:17423.

Thompson AD, Picard N, Min L, Fagiolini M, Chen C (2016) Cortical Feedback Regulates Feedforward Retinogeniculate Refinement. Neuron 91:1021-1033.

Ting JT, Daigle TL, Chen Q, Feng G (2014) Acute brain slice methods for adult and aging animals: application of targeted patch clampanalysis and optogenetics. Methods Mol Biol Clifton NJ 1183:221-242.

Ting JT, Lee BR, Chong P, Soler-Llavina G, Cobbs C, Koch C, Zeng H, Lein E (2018) Preparation of Acute Brain Slices Using an Optimized N-Methyl-D-glucamine Protective Recovery Method. JoVE J Vis Exp:e53825.

Turrigiano G (2012) Homeostatic Synaptic Plasticity: Local and Global Mechanisms for Stabilizing Neuronal Function. Cold Spring Harb Perspect Biol 4:a005736-a005736.

Turrigiano GG (1999) Homeostatic plasticity in neuronal networks: the more things change, the more they stay the same. Trends Neurosci 22:221-227.

Turrigiano GG (2008) The Self-Tuning Neuron: Synaptic Scaling of Excitatory Synapses. Cell 135:422435.

Turrigiano GG, Leslie KR, Desai NS, Rutherford LC, Nelson SB (1998) Activity-dependent scaling of quantal amplitude in neocortical neurons. Nature 391:892-896.

Turrigiano GG, Nelson SB (2004) Homeostatic plasticity in the developing nervous system. Nat Rev Neurosci 5:97-107.

Vaughn JE, Barber RP, Sims TJ (1988) Dendritic development and preferential growth into synaptogenic fields: A quantitative study of Golgi-impregnated spinal motor neurons. Synapse 2:69-78.

Venkatesan S, Subramaniam S, Rajeev P, Chopra Y, Jose M, Nair D (2020) Differential Scaling of Synaptic Molecules within Functional Zones of an Excitatory Synapse during Homeostatic Plasticity. eNeuro 7 Available at: https://www.eneuro.org/content/7/2/ENEURO.0407-19.2020 [Accessed October 20, 2020].

Wallace W, Bear MF (2004) A Morphological Correlate of Synaptic Scaling in Visual Cortex. J Neurosci 24:6928-6938.

Wierenga CJ, Ibata K, Turrigiano GG (2005) Postsynaptic Expression of Homeostatic Plasticity at Neocortical Synapses. J Neurosci 25:2895-2905. 
Wilding LA, Uchihashi M, Bergin IL, Nowland MH (2015) Enucleation for Treating Rodent Ocular Disease. J Am Assoc Lab Anim Sci JAALAS 54:328-332.

You Y, Gupta VK, Graham SL, Klistorner A (2012) Anterograde Degeneration along the Visual Pathway after Optic Nerve Injury. PLoS ONE 7 Available at: https://www.ncbi.nlm.nih.gov/pmc/articles/PMC3530579/ [Accessed August 4, 2020].

Yücel YH, Zhang Q, Weinreb RN, Kaufman PL, Gupta N (2001) Atrophy of relay neurons in magno- and parvocellular layers in the lateral geniculate nucleus in experimental glaucoma. Invest Ophthalmol Vis Sci 42:3216-3222.

Zhang XM, François U, Silm K, Angelo MF, Fernandez-Busch MV, Maged M, Martin C, Bernard V, Cordelières FP, Deshors M, Pons S, Maskos U, Bemelmans AP, Wojcik SM, El Mestikawy S, Humeau Y, Herzog E (2019) A proline-rich motif on VGLUT1 reduces synaptic vesicle superpool and spontaneous release frequency Westbrook GL, Jahn R, Milovanovic D, eds. eLife 8:e50401. 


\section{$\underline{\text { Table } 1 \text { - mEPSC properties. }}$}

\begin{tabular}{|c|c|c|c|c|c|c|c|c|c|c|c|c|c|}
\hline & $\begin{array}{l}\text { frequenc } \\
\mathrm{y}(\mathrm{Hz})\end{array}$ & $\begin{array}{l}\text { t- } \\
\text { test }\end{array}$ & $\begin{array}{l}\text { K-S } \\
\text { test }\end{array}$ & $\begin{array}{l}\text { amplitud } \\
\text { e (pA) }\end{array}$ & $\begin{array}{l}\text { t- } \\
\text { test }\end{array}$ & $\begin{array}{l}\text { K-S } \\
\text { test }\end{array}$ & $\begin{array}{l}\text { Decay } \\
\text { time } \\
(\mathrm{ms})\end{array}$ & $\begin{array}{l}\text { t- } \\
\text { test }\end{array}$ & $\begin{array}{l}\text { K-S } \\
\text { test }\end{array}$ & $\begin{array}{l}\text { charge } \\
\text { (fC) }\end{array}$ & $\begin{array}{l}\text { t- } \\
\text { test }\end{array}$ & $\begin{array}{l}\text { K-S } \\
\text { test }\end{array}$ & $\mathbf{n}$ \\
\hline $\begin{array}{l}\text { Contro } \\
1\end{array}$ & $21.8+3.8$ & & & $9.1 \pm 0.5$ & & & $\begin{array}{l}3.5 \pm 0 . \\
2\end{array}$ & & & $\begin{array}{l}29.7 \pm 1 . \\
2\end{array}$ & & & 11 \\
\hline 2 days & $14.6+3.0$ & 0.38 & $\begin{array}{l}0.011 \\
1\end{array}$ & $9.4 \pm 0.7$ & $\begin{array}{l}0.9 \\
7\end{array}$ & 0.05952 & $\begin{array}{l}3.9+0 . \\
3\end{array}$ & $\begin{array}{l}0.6 \\
9\end{array}$ & 0.0023 & $\begin{array}{l}36.8 \pm 6 . \\
2\end{array}$ & 0.6 & 0.0246 & 13 \\
\hline 7 days & $17.0+4.1$ & 0.78 & $\begin{array}{l}< \\
0.000 \\
1\end{array}$ & $11.7+0.9$ & $\begin{array}{l}0.0 \\
7\end{array}$ & $\begin{array}{l}<0.000 \\
1\end{array}$ & $\begin{array}{l}4.2+0 . \\
4\end{array}$ & $\begin{array}{l}0.4 \\
2\end{array}$ & $\begin{array}{l}<0.000 \\
1\end{array}$ & $\begin{array}{l}45.3+4 . \\
7\end{array}$ & $\begin{array}{l}0.0 \\
2\end{array}$ & $\begin{array}{l}<0.000 \\
1\end{array}$ & 12 \\
\hline $\begin{array}{l}14 \\
\text { days }\end{array}$ & $15.6 \pm 1.8$ & 0.4 & $\begin{array}{l}< \\
0.000 \\
1\end{array}$ & $9.5 \pm 0.5$ & 0.9 & 0.4583 & $\begin{array}{l}4.6 \pm 0 . \\
4\end{array}$ & $\begin{array}{l}0.0 \\
7\end{array}$ & $\begin{array}{l}<0.000 \\
1\end{array}$ & $\begin{array}{l}37.5 \pm 3 . \\
7\end{array}$ & $\begin{array}{l}0.1 \\
9\end{array}$ & $\begin{array}{l}<0.000 \\
1\end{array}$ & 6 \\
\hline
\end{tabular}

Table 2 - Paired pulse ratio.

\begin{tabular}{|l|l|l|l|l|l|l|l|l|}
\hline Stimulus intervals & $\mathbf{1 0 0} \mathbf{~ m s}$ & $\mathbf{p}$ (t-test) & $\mathbf{2 0 0} \mathbf{~ m s}$ & $\mathbf{p ~ ( t - t e s t )}$ & $\mathbf{5 0 0} \mathbf{~ m s}$ & $\mathbf{p}(\mathbf{t}-$ test) & $\mathbf{1 0 0 0} \mathbf{~ m s}$ & $\mathbf{p ~ ( t - t e s t )}$ \\
\hline Control & $0.54 \pm 0.03$ & & $0.51 \pm 0.03$ & & $0.60 \pm 0.03$ & & $0.69 \pm 0.03$ & \\
\hline $\begin{array}{l}2 \text { days post- } \\
\text { enucleation }\end{array}$ & $0.42 \pm 0.05$ & 0.06 & $0.54 \pm 0.03$ & 0.52 & $0.58 \pm 0.03$ & 0.65 & $0.62 \pm 0.04$ & 0.18 \\
\hline
\end{tabular}

$\underline{\text { Table } 3 \text { - Evoked spiking. }}$

\begin{tabular}{|l|l|l|l|l|l|}
\hline & $\mathbf{I}_{\mathbf{5 0}} \mathbf{( p A )}$ & $\mathbf{p}$ (t-test) & $\mathbf{A U C}(\mathbf{p A}$ *spikes) & $\mathbf{p}(\mathbf{t}-\mathbf{t e s t})$ & $\mathbf{n}$ \\
\hline Control & $135_{ \pm}+10$ & & $2960 \pm 335$ & & 13 \\
\hline 2-4 days post-enucleation & $114 \pm 13$ & 0.54 & $3606 \pm 343$ & 0.46 & 15 \\
\hline $7-10$ days post-enucleation & $84 \pm 7$ & 0.002 & $4949 \pm 631$ & 0.03 & 14 \\
\hline $14-16$ days post-enucleation & $83 \pm 11$ & 0.01 & $4596 \pm 380$ & 0.02 & 7 \\
\hline
\end{tabular}


bioRxiv preprint doi: https://doi.org/10.1101/2020.11.02.365130; this version posted November 2, 2020. The copyright holder for this preprint (which was not certified by peer review) is the author/funder. All rights reserved. No reuse allowed without permission. 